\title{
PRÓXIMA PUBLICACIÓN DE LA TRADUCCIÓN ESPAÑOLA DE LOS FRAGMENTOS PÓSTUMOS DE F. NIETZSCHE
}

- Volumen I (KSA 7). Edición de Luis Enrique de Santiago Guervós

- Volumen IV (KSA 12 y 13). Edición de Joan B. Llinares y Juan L. Vermal.

- Madrid: Editorial Tecnos

Auspiciada por la Sociedad Española de Estudios sobre Nietzsche "SEDEN《, se está realizando la edición íntegra de los Fragmentos póstumos de Nietzsche, redactados entre 1869 y 1889. Esta edición, aunque seguirá el texto establecido por la gran edición alemana de Giorgio Colli y Mazzino Montinari, se pretende realizar con criterios propios de edición siguiendo una metodología y un plan de trabajo que están siendo acordados por el equipo responsable del proyecto.

No es necesario subrayar la importancia de esta edición, pues ante la indiscutible relevancia cultural del pensamiento de Nietzsche y ante el elevado interés que suscita resulta obvia la necesidad de disponer de una edición textualmente fiable e íntegra en español de sus escritos, edición ya existente desde hace muchos años en las grandes lenguas de la cultura europea: francés, inglés, italiano, alemán, e incluso en otras como el japonés. La situación en nuestro país, en este sentido, deja bastante que desear. Contamos con ediciones muy buenas de casi todas las obras publicadas por Nietzsche, en especial las que se deben al trabajo de Andrés Sánchez Pascual. Otros autores van completando esta tarea acometiendo la traducción de escritos también significativos y muy pertinentes, como los Escritos sobre retórica (ed. Luis de Santiago Guervós, Trotta), Escritos sobre Wagner (ed. Joan B. Llinares, Biblioteca Nueva), Humano, demasiado humano (ed. M. Barrios y A. Brotons, Akal), El culto griego a los dioses (ed. Diego Sánchez Meca, Alderabán), Sobre verdad y mentira y la Segunda consideración intempestiva (ed. Joan B. Llinares, Península), Aurora (ed. G. Cano, Biblioteca Nueva) o Schopenhauer como educador (ed. J. Muñoz, Biblioteca Nueva). Pero en lo referente a los Fragmentos póstumos (cuya amplitud e importancia para la comprensión de la obra nietzscheana es tan grande como la de las obras publicadas) nos encontramos con una carencia casi total de buenas ediciones. En realidad no se ha acometido todavía ningún proyecto de edición en castellano de la totalidad de este legado póstumo. Este esfuerzo sigue sin hacerse en lengua castellana.

Y al no existir esta edición crítica de los póstumos, los jóvenes y estudiosos de nuestro país, de toda la América latina y, en general, los hispanoparlantes de cualquier parte del mundo interesados en Nietzsche, tienen que recurrir, si no leen alemán, o a traducciones en las otras lenguas o a la muy parcial y defectuosa traducción castellana de la por muchos motivos insatisfactoria edición de los textos 
póstumos de la Grossoktavausgabe llevada a cabo por Eduardo Ovejero y Maury en 1925, y publicada en Buenos Aires bajo el pomposo título de Obras completas. Es una edición defectuosa básicamente por el seccionamiento arbitrario de gran número de fragmentos, por la inexacta reproducción de la numeración original de los aforismos y por sus continuos descuidos y errores en el desciframiento de los manuscritos registrados en la misma edición alemana que le sirvió de base. Esta y otras que la reproducen en forma de selección o antología carecen de los criterios filológicos elementales y han sido hechas sin pretensión alguna de rigor. Su única justificación remite al motivo tan clásico como absurdo de permitir una lectura 'accesible y fácil' de los textos de Nietzsche. A esta tan precaria situación pretende dar solución nuestra „SEDEN« llevando a cabo una traducción de la integridad de los Fragmentos póstumos a partir de las mejores ediciones alemanas hoy existentes.

En estos momentos se encuentran ya en imprenta los volúmenes I (KSA 7) y IV (KSA 12 y 13), que posiblemente estarán en las librerías a finales de 2005. Los otros dos volúmenes, el II (KSA 8 y 9, editados por Manuel Barrios y Juan Antonio Rodríguez Tous) y el III (KSA 10 y 11, editados por Diego Sánchez Meca y Jesús Conill), se publicarán a partir del año 2006. Con este trabajo se cubrirá una carencia importante al poner a disposición del público hispano-parlante una edición crítica, fiel y completa del Nachlass nietzscheano, ya existente desde hace muchos años en las demás lenguas importantes de la cultura europea. Trataremos de que aporte los medios (aparato crítico y comentarios) estrictamente necesarios requeridos por una edición merecedora del nombre de crítica, con una elaboración propia y actualizada de la documentación sobre el contexto y el proceso de elaboración de los textos, aprovechando la diversa investigación realizada ya sobre el particular. Así contribuiremos a introducir posibilidades de una mayor calidad y rigor en los trabajos y estudios que, con tanta frecuencia, se llevan a cabo en nuestro país sobre el pensamiento de Nietzsche (tesis doctorales, cursos, monografías, artículos, debates, etc.), dado el sostenido interés que el pensamiento y la obra de este pensador siguen suscitando entre nosotros.

Diego Sánchez Meca

Presidente de SEDEN, Director del Proyecto 